-

colobal bumatit

(6)

\title{
The use of Twitter and Facebook Social Media in Communicating \& Disseminating Weather and Climate Information by Kenya Meteorological Department
}

By Misiani Zachary, Lun Yin, Mwai Zacharia, Xiaohan Zhang, Yanyan Zheng, Antonine Sakwa, Collison Lore \& Marta Baraibar

Southwest Forestry University

Abstract- Today, traditional media is still a significant part of disseminating weather and climate information, still they have not been able to reach out to all users of the target audience alone. On the other hand, social media platforms such as Twitter, Facebook, YouTube, Instagram, etc. are used as a tool of communicating weather and climate information to various users in a wellorganized manner like never before. Using a scientific research methodology of case study, the research was designed to explore how the Kenya Meteorological Department (KMD) is using Twitter and Facebook accounts for weather and climate information dissemination to various users.

Keywords: social media, twitter, facebook, KMD.

GJSFR-H Classification: FOR Code: 960399

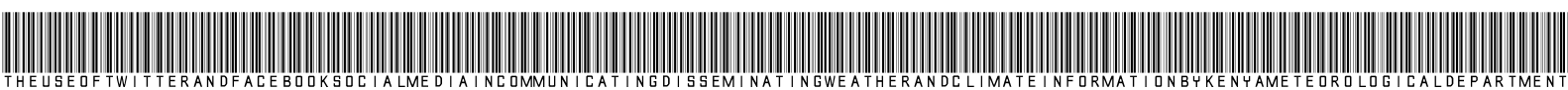

Strictly as per the compliance and regulations of:

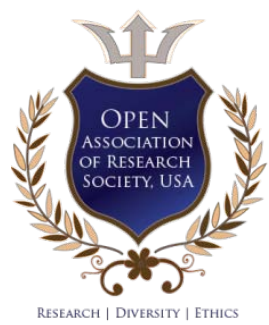

(C) 2020. Misiani Zachary, Lun Yin, Mwai Zacharia, Xiaohan Zhang, Yanyan Zheng, Antonine Sakwa, Collison Lore \& Marta Baraibar. This is a research/review paper, distributed under the terms of the Creative Commons Attribution-Noncommercial 3.0 Unported License http://creativecommons.org/licenses/by-nc/3.0/), permitting all non commercial use, distribution, and reproduction in any medium, provided the original work is properly cited. 


\title{
The use of Twitter and Facebook Social Media in Communicating \& Disseminating Weather and Climate Information by Kenya Meteorological Department
}

\author{
Misiani Zachary ${ }^{\alpha}$, Lun Yin ${ }^{\sigma}$, Mwai Zacharia ${ }^{\rho}$, Xiaohan Zhang $^{\omega}$, Yanyan Zheng ${ }^{\ddagger}$, Antonine Sakwa ${ }^{\S}$, \\ Collison Lore ${ }^{x} \&$ Marta Baraibar ${ }^{v}$
}

Abstract- Today, traditional media is still a significant part of disseminating weather and climate information, still they have not been able to reach out to all users of the target audience alone. On the other hand, social media platforms such as Twitter, Facebook, YouTube, Instagram, etc. are used as a tool of communicating weather and climate information to various users in a well-organized manner like never before. Using a scientific research methodology of case study, the research was designed to explore how the Kenya Meteorological Department (KMD) is using Twitter and Facebook accounts for weather and climate information dissemination to various users.

The researchers analyzed data for the Social Set Analysis (SSA) and Event Study Methodology (ESM), which are two components of social media analytical tools. The results found out that the majority $(71 \%)$ users of weather and climate information were male in the age bracket of (25-34) who mostly are residents of Nairobi county. The study sample was made from 26,343 KMD Facebook followers with 25,597 total Facebook page likes, while Twitter Account had 22,700 followers. Hence, the conclusion that social media is a positive influence tool for sharing weather and climate information by KMD. In so doing, the study has suggested that these social media platforms should be enhanced to increase users' engagement in creating weather/climate contents according to the user needs/ and combining traditional media with social media.

Keywords: social media, twitter, facebook, KMD.

Author a $\rho:$ Kenya Meteorological Department, Ministry of Environment and Forestry, Nairobi, Kenya. e-mails: zacharymisiani@gmail.com, lun.yin@gmail.com

Author a w: Center for Biodiversity and Indigenous Knowledge, Kunming, China.

Author o: Center for Ecological Civilization, School of Geography and Ecotourism, Southwest Forestry University, Kunming, China.

Author o: Southwest Regional Ecological Civilization and Environmental Rule of Law Research Center, Leshan Normal University, Leshan, China.

Author ¥: Yunnan People’s Publishing House Ltd, Kunming, China.

Author \&: Institute for Meteorological Training and Research, Nairobi, Kenya.

Author $\chi v$ v: IGAD Climate Prediction and Applications Centre, Nairobi, Kenya.

\section{InTRODUCTION}

espite a significant advance in weather
forecasting and climate prediction,
improvements in the accuracy of weather warnings, heavy rainfall remains a serious threat to the safety of the lives and properties of Kenyan citizens. By the end of April 2020 alone, Kenya Meteorological Department-KMD issued 4 "Heavy Rainfall Alerts" in Kenya, which were responsible for more than 164 fatalities, with more than 20,000 people left homeless, while the lucky ones seeking refuge in schools while millions of property and acres of crops damaged according to Hon. Eugene Wamalwa, the Cabinet Secretary for Devolution. (https://www.nation.co.ke/ news/Heavy-rains-kill-194-Kenyans/1056-5544130-2bkd 9fz/index.html)

In such a situation like the April scenario, effective communication between weather and climate providers of hazardous weather information such as meteorologist and weather users, represents a critical variable that can limit the socioeconomic of heavy rains, floods, mudslide, landslide, and lightening among other weather disasters (Severe 2002, Huang 2019). In short form, communication indicates an exchange of information among entities, organizations, or communities. In the context of weather and climate information, weather alerts represent a basic yet essential form of communication wherein KMD forecasters inform Kenyan people of the potential for or imminence of weather-related hazards.

This communication and dissemination of weather are only valuable if the targeted people are able to get this information at right time; they pay attention to it, and understands the weather information. It is fruitless if the targeted people do not receive, attend to, or understand the information being conveyed. People are unlikely to engage in the actions necessary to protect themselves from heavy rains if they do not receive, attend to, or understand information provided by KMD. Up-to-date, researchers who are interested in public responses to weather and climate information have 
focused most of their efforts on the factors that influence communication reception and understanding (Macleod et al. 2020).

These endeavors have produced several significant insights. For example, existent research on reception proves that members of the public are significantly less likely to receive weather information that are conveyed during night hours (Thesis et al. 2015). Researchers have also shown that the socioeconomic position of people influences the extent by which people understand the information conveyed in warnings. Adding more complex details such as the possibility of a particular event/ or phenomenon can also impact the possibility that people will acknowledge it (Joslyn and Savelli 2010). However, this study neglects the attention part of the communication equation.

Consequence, little is known about the aspects that influence public attention to messages issued by KMD professionals. Who pays attention to weather warnings and climate information? How does it vary across space and time? Does message content and mode of delivery influence the extent to which people pay attention to information about severe weather and rainfall alerts? Scientists have yet to answer these and other vital questions about public attention to the communication of weather for several reasons, some of which involve data limitations.

In simple language, scientists have ignored public's attention because they have yet to develop acceptable measure of the concept. In an effort to get a better of option for this constraint, the research develops a new indicator of public attention to weather and climate information communication that based on the growing stream of real time data that followers of the public publish on social media platforms, which in this case, are Facebook and Twitter accounts (Management, Management, and Management 2014).

Although social media has increased its popularity as a promising channel to expand the horizon of weather and climate information, the social inequality in the usage of social media data should make us cautious about the use of these tools for such purposes (Slater, Angl, and Leung 2016).

The rationale for this study was motivated by a personal interest in social media, especially Twitter and Facebook, and also the desire to investigate the impact these two-social media has on sharing weather and climate information perspective by KMD.

In this study, we utilize Social Set Analysis (SSA) and Event Study Methodology (ESM) models to understand the social and spatial inequities in the generation of tweets and Facebook messages before, during, and after event/ weather forecast. This model goes beyond the "digital divide" to explain the spatial heterogeneity in the usage of social media (Odhiambo 2012).
Explicitly, this study seeks to answer the following research queries: What factors affect the number of tweets and Facebook messages generated before, during and, after event/disaster? What factors explain the spatial variation in the number of tweets and Facebook messages posted before, during and, after a disaster? This study analyzed tweets \& Facebook messages generated from KMD social media official accounts to empirically test our model (Ali et al. 2016).

\section{il. Methodology and Data}

\section{a) Social Set Analysis-SSA}

Social Set Analysis, as employed in this research, is concerned with the mobility of social users across time and space. For mobility across time, we conduct SSA on KMD social data from the Facebook walls with an analytical focus on the set of users that interacted with KMD between 1st January 2019 to 31st March 2020 events and set-theoretical intersections of this period. Similarly, for mobility across space, we conducted set inclusions and exclusion of users who interacted with the KMD Facebook wall. SSA allows us to uncover not only the interactional dynamics over time and space but also identify user's sets that correspond to targeting segmentations such as social activists (Flesch and Vatrapu 2016).

\section{b) Event Study Methodology}

Event studies are methodology to assess an impact, especially on "KMD Heavy Rainfall Alerts" messages, which KMD posted on social media. Without exception structure for occurrence study methodology, at a higher level of abstraction, it contains identifying three periods. First, defining an event of interest and identifying the period over which it is active (event window), the second involves identifying the estimation period for the event (pre-event or estimation window) and the final one being identifying the post-event window (Flesch and Vatrapu 2016).

The social set analysis of a real-world event, the study has applied event study methodology to identify the three periods of user's interactions on KMD social media platforms: before (pre-event window), during (event window), and after (post-event window) (Xiao, Huang, and Wu 2015).

\section{c) Data Acquisition}

The study's analyses are based exclusively on primary data collected through Social Data Analytics Tool for both Facebook and Twitter accounts (Babu, S, and Harikrishnan 2019). This tool provided activity datasets that were generated as independent files and combined into one for using them as a whole data set that can be filtered or expanded on demand (Lu n.d.). 


\section{ResEARCH Findings AND AnALYsis}

By the time the research was conducted, the Facebook page had 26,343 followers with 25,597 total likes, while Twitter Account had 22,700 followers. To evaluate the influence of social media platforms, the day-to-day figures of followers and posts were gotten from the Facebook and Twitter accounts between 1st January 2019 to 31st March 2020. The reach of a post on Facebook was defined as the number of views each post received during the study period, as reported on Facebook analytics (Slater, Angl, and Leung 2016). They included all posts viewed by people on more than one device such as use of a desktop, computers, mobile devices or laptops. "Followers" were defined as a person or organization that 'liked' or 'followed' one of these social media accounts (Cody et al. 2015).

\section{a) Daily Twitter Activity}

To determine the temporal dynamics associated with KMD weather and climate information, the study created a set of variables that count the number of daily tweets impressions, daily tweets engagements, daily tweets media views, daily tweets retweets, daily tweets replies, and daily tweets likes on each day of our analysis.

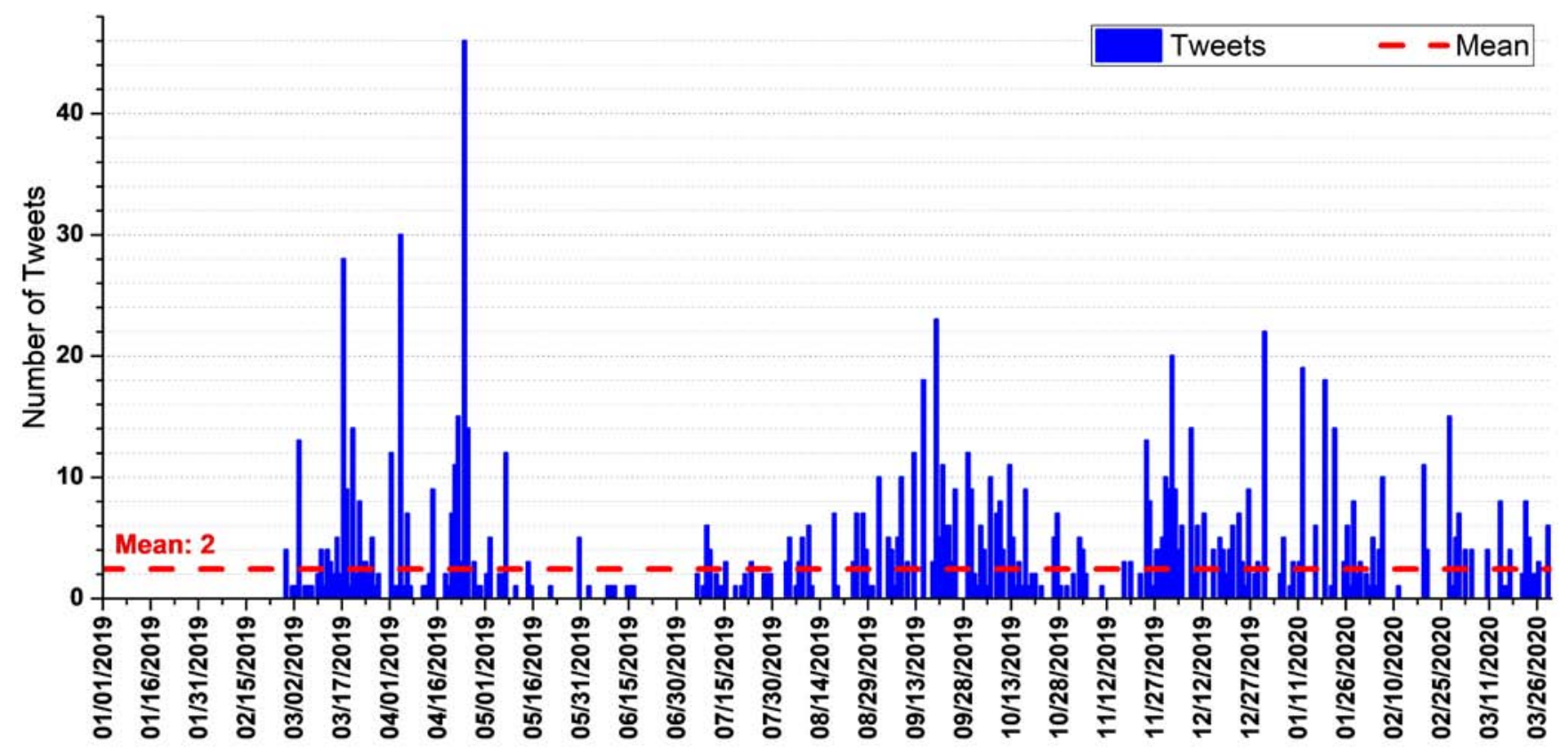

Figure 1: Daily number of Tweets (1stJan 2019-31st March 2020)

From the Figure 1, we collected and archived 1,102 tweets and associated metadata that were published by KMD from 1st January 2019to 31st March 2020. The largest number of tweets was recorded on 25th April 2019 with a record of 46 tweets in a day followed by 30 tweets on 5th April 2019. The third, fourth, and fifty tweets of 28, 23, and 22 were recorded on 18th March 2019, 20th September 2019, and 1st January 2020, respectively. As shown in Figure 1, the broken red line indicates an average of 2 tweets published per day (24-h EAT period) during this period. The inactive days were January and February 2019, where there were no published tweets. 


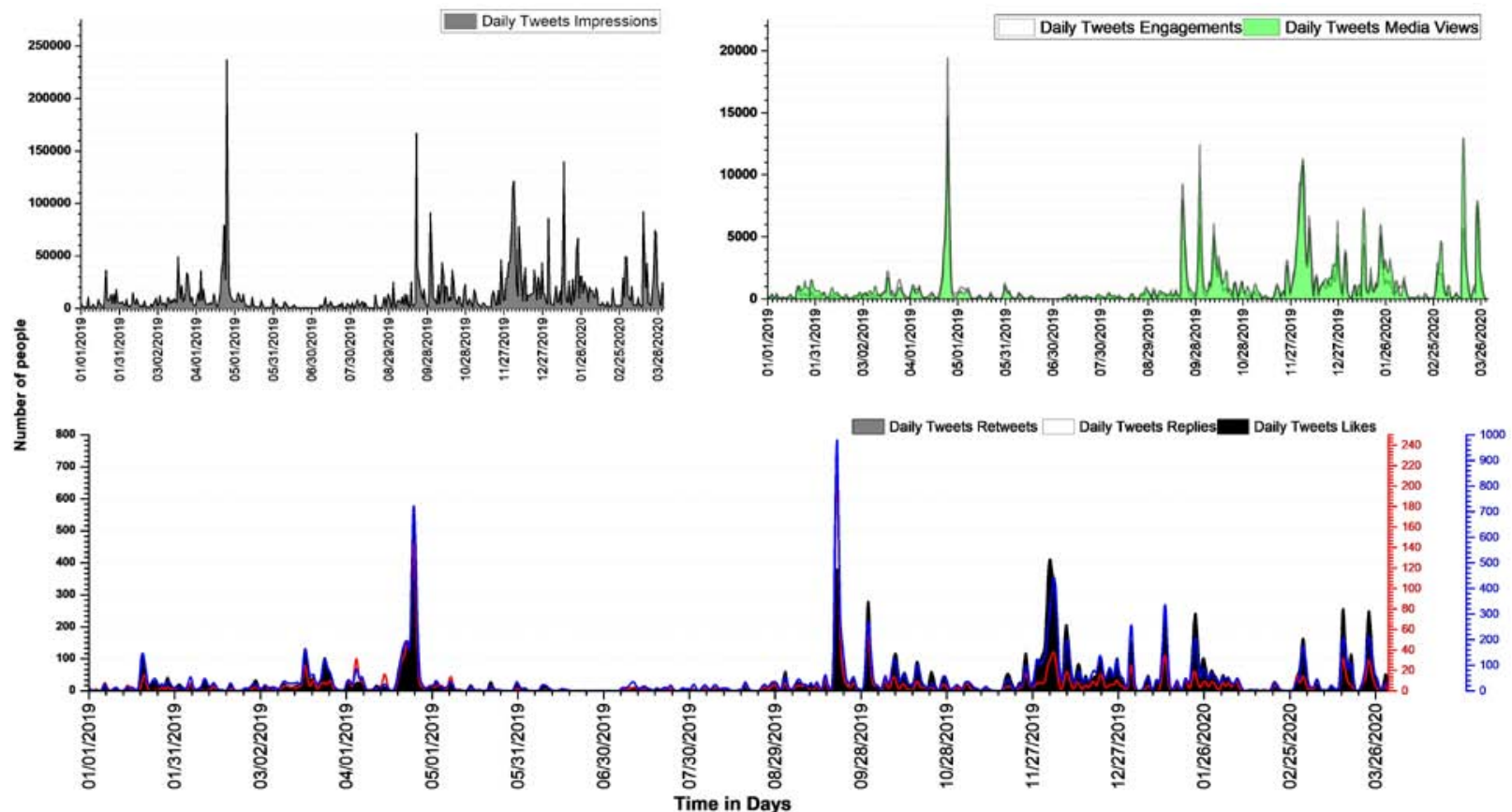

Figure 2: Temporal Comparison of Twitter Activity: Daily Tweets Impressions, Engagements, Media Views, Retweets, Replies and Likes (Jan 2019 - March 2020)

Figure 2 shows the activities on twitter account increasing according to the number of tweets with local significance and intensity of events. Figure 2(a) shows the distribution of daily tweets impression while the Figure 2(b) shows the daily tweets engagements and media views in contrast Figure 2(c) shows the daily tweets retweets, tweet replies, and tweets likes over the study period analyzed and confirms the volume effect in line with the actual timeline of tweets Figure 1. The peak of Twitter activity during the periods of (25th April-2019, 20th Aug-2019, 5th Dec-2019, and 24th March-2020) was recorded more than 10,000 online engagements, while it was also observed during (3rd Dec-2019, 6th Dec-2019, 26th April-2019, 1st Jan-2020, 13th Jan-2020, 15th March-2020, 4th Dec-2019, 25th -March-2020, 24th Jan-2020, 23rd April-2019, 9th Dec-2019, 16th March2020, 21st Sep-2019, 1st Oct-2019, 23rd Jan-2020, 25th Nov-2019, 10th Dec-2019, and 10th Oct-2019) more than 5,000 online engagements was recorded Figure 2. This period corresponds to the number of tweets that were posted online in Figure 1. This graph indicates that, the more the tweets the more engagements between KMD and followers/users.

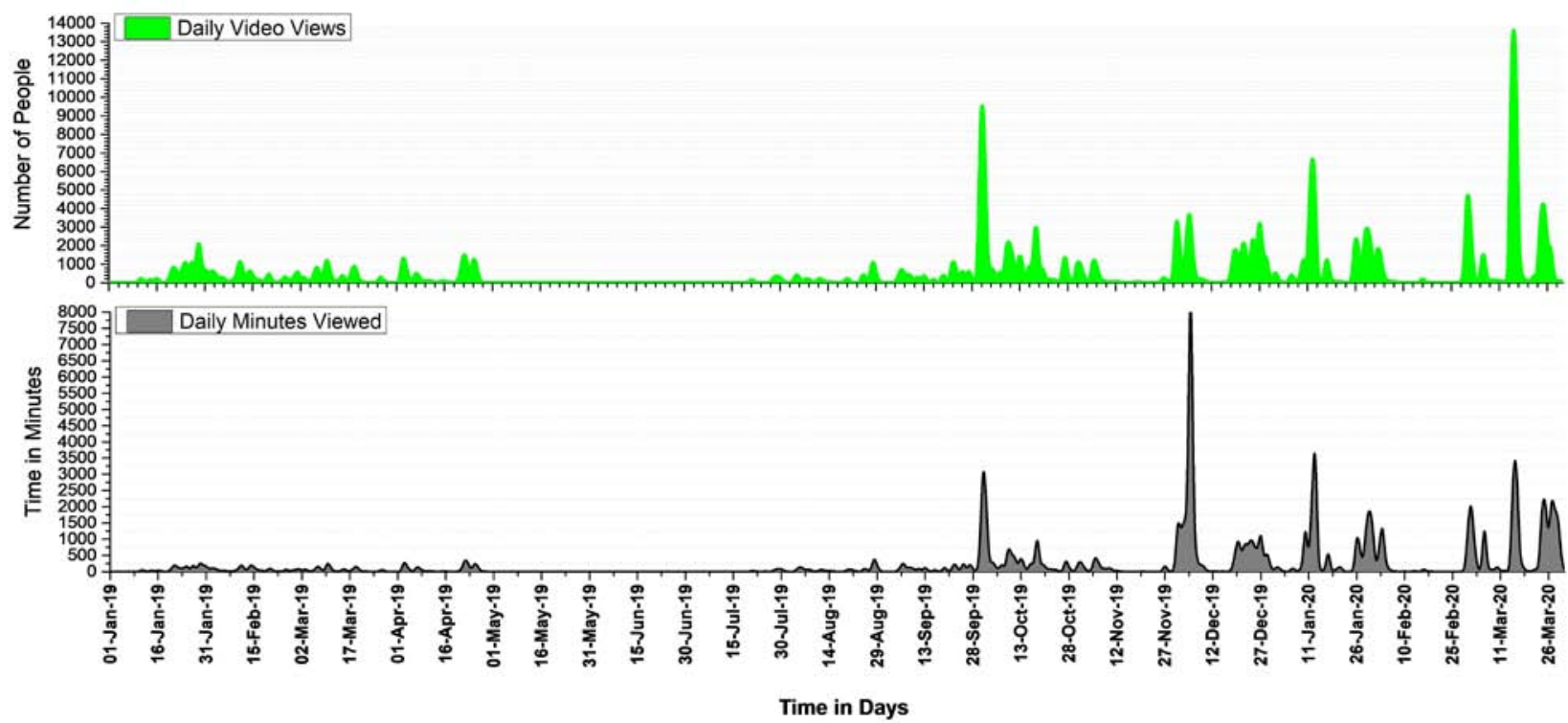

Figure 3: Iemporal variation ot daily video views and minutes viewed 
Figure 3 plots daily video views and daily minute's views comparatively over time. These figures reveal preliminary support for the supposition that daily video views and minutes viewed counts correspond with the number of tweets issued on a given day. Although the public response from users from different categories cannot be measured in detail, if the study considers retweets Figure 2(c) and Figure 3 as an indicator of influence (Barnett, Bigdeli, and Sams 2016), it seems that factual information during posting messages had the impact.

b) Daily Facebook Page Activity

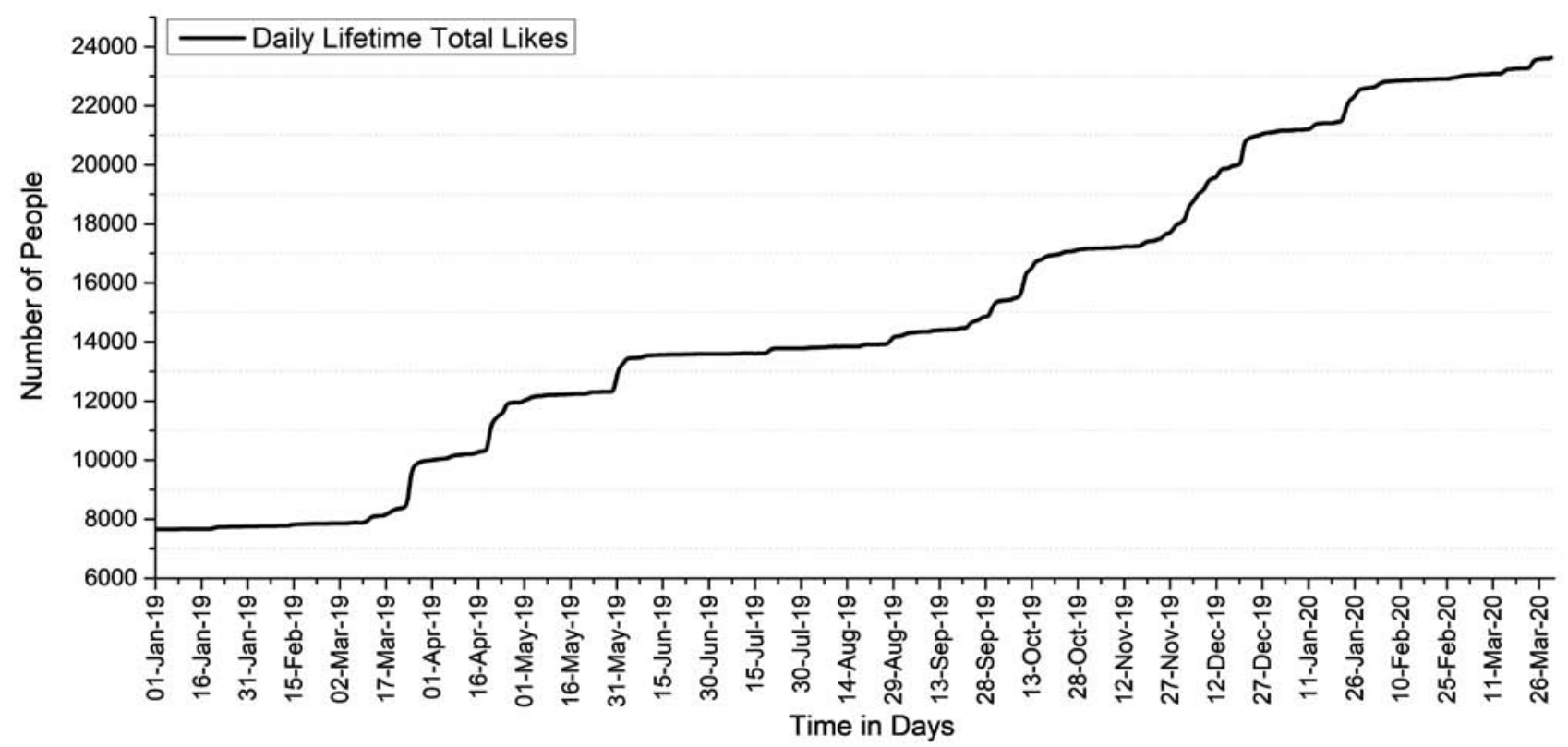

Figure 4: Number of Facebook daily lifetime total likes on the KMD account between the study periods

To assess the impact of the social media platform, the daily number of KMD Facebook page likes and posts were obtained between 1st Jan 2019 and 31st March 2020. It was noticed that there was rise in the number of likes on the KMD Facebook page account each day, as reported on Facebook analytics Figure 4.

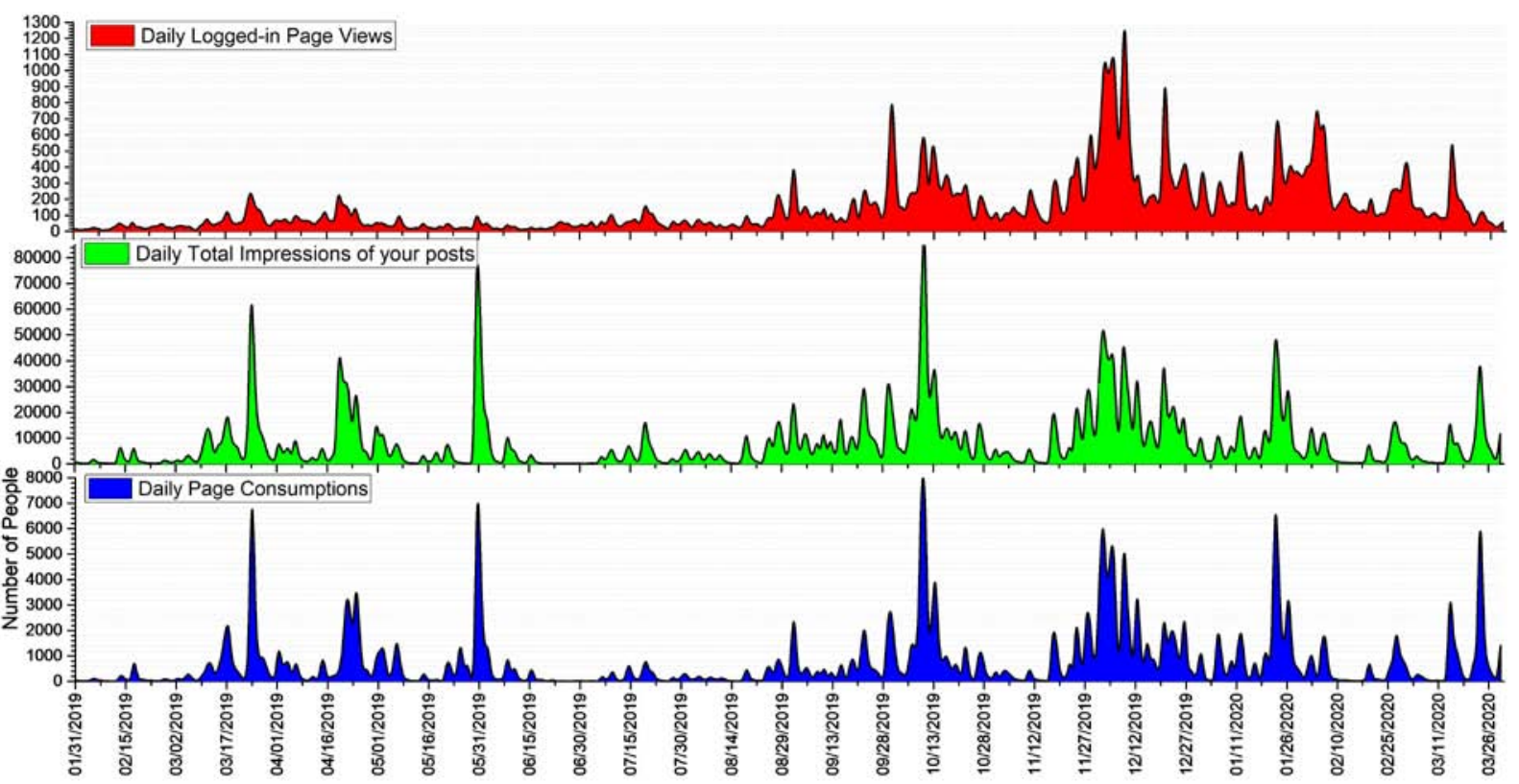

Figure 5: A temporal comparison of daily logged-in, impression, consumption counts, and the number of people who accessed the weather and climate information 
Having analyzed the total daily likes on KMD Facebook page, which showed a gradual increase of followers from the beginning of the study period, the study turns now to the number of people who logged-in, these people who were impressed by KMD post and lasting the number of people who consumed the message each day. Again, Figure 5 lends preliminary, but lastly, support for the concept that the number of people who viewed weather and climate information on a given day on Facebook, provides a valid indicator of public attention corresponding with the number of messages posted that day Figure 8. It can be realized that the highest number of users who logged-in to the KMD Facebook page was on 9th Dec 2019 with 1513 people followed by 1180, 1115, 1148, and 1048 on 21st Dec 2019, 3rd Dec 2019, 06th Dec 2019, and 5th Dec 2019, respectively. The highest number of the impressed people was realized on 10th Nov 2019 with a total number of 105,461 , followed by 95,296 and 81,148 on 31st May 2019 and 25th March 2019, respectively. Lastly, the highest number of people who consumed the message was on 25th March 2019 with 9310 followed by 9270 and 8622 on 31st May 2019, and 22nd Jan 2019 respectively.

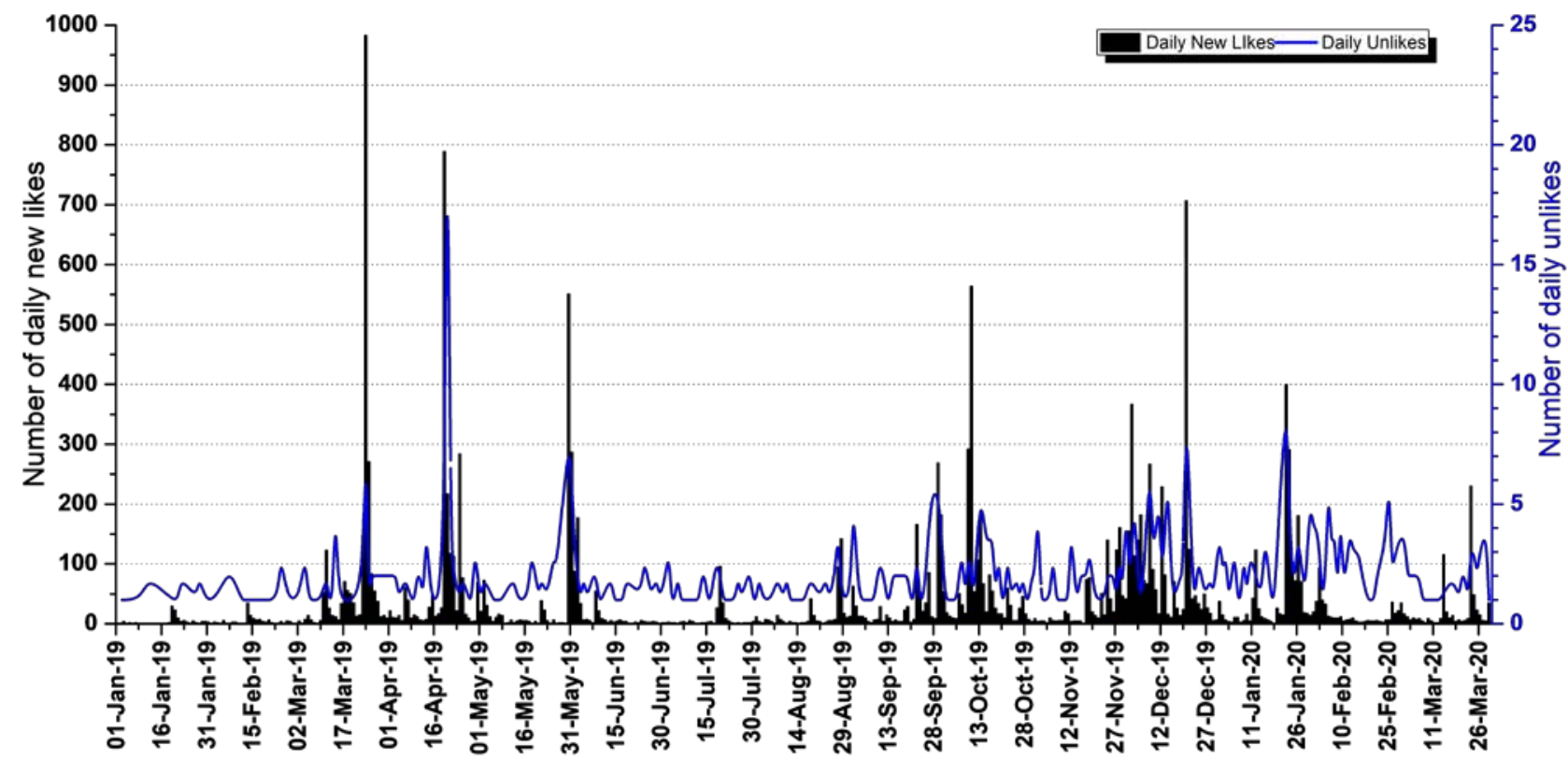

Figure 6: A temporal comparison of daily new likes and unlike counts

The Facebook account allows us to assess in detail the impact of each message or post both in realtime and from the moment it was posted to days, weeks, and months afterward. The Audience Insights from KMD Facebook were used to monitor communications. Since the simple statistical analysis of outreach was insufficient to gain a proper insight Figure 4, Figure 5 and the study needed to understand also the semantics of messages so that we can better correlate weather and climate information with environmental behavior, i.e. not just whether followers respond to a post, but how they responded Figure 5, Figure 6, Figure 7, Figure 8 and Figure 9.

From the quantitative aspects Figure 6, the number of daily new likes and unlikes was plotted. It can be realized that there was an increase of daily new likes, which was more than daily unlikes. The highest daily new likes were observed on 25th March-2019 with 983 new likes, followed by 789 on 20thApril-2019 and thirdly 707 on 21st Dec-2019. The highest number of unlikes was also considered. On 21stApril-2019 recorded the highest number of unlikes 23 , followed by 10 , on 21 st Dec-2019 and 23rd Jan-2020 each. 


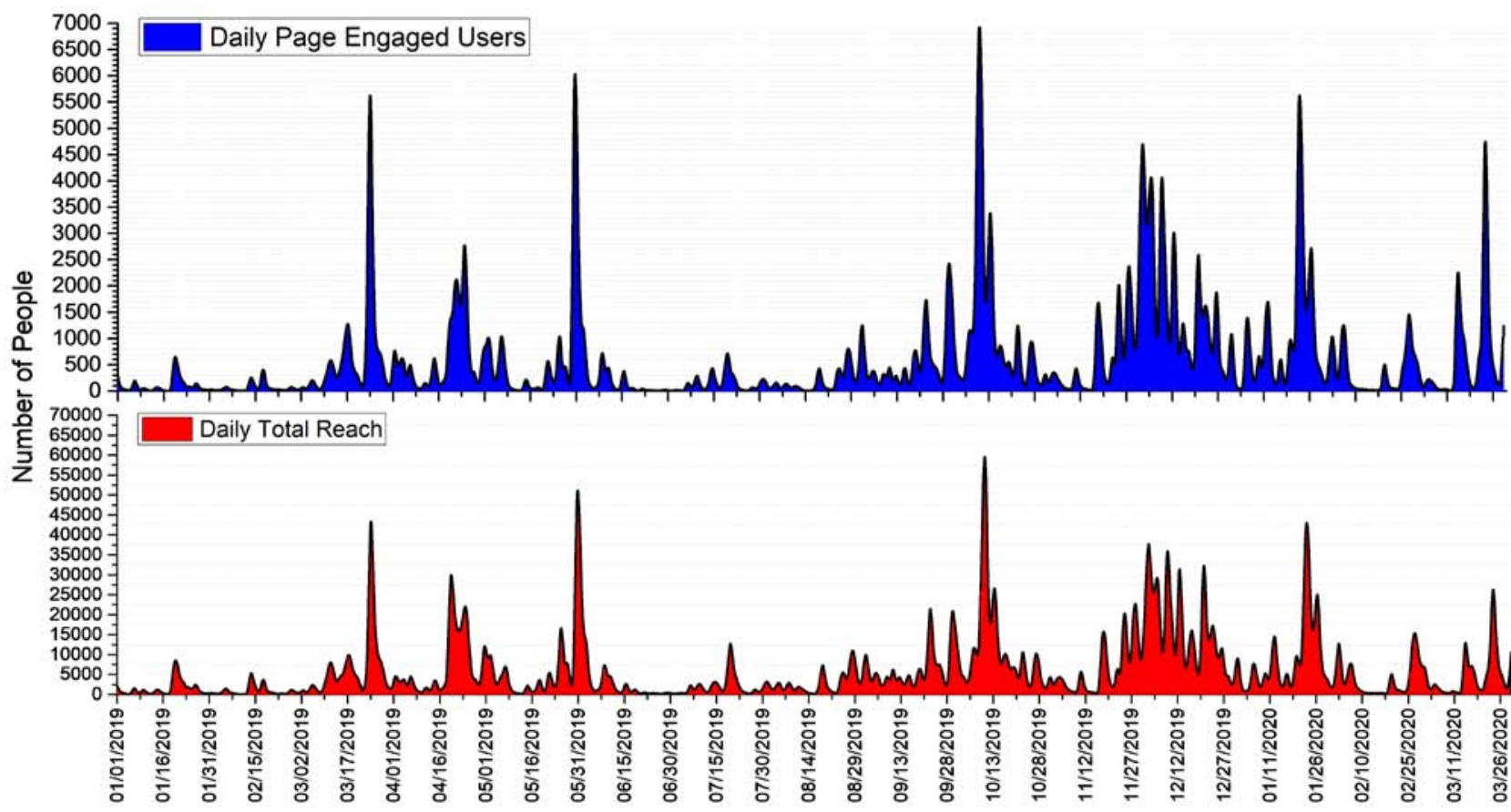

Figure 7: Daily count for KMD Facebook page engaged users and total reach

Figure 7 gives the daily Facebook engaged users and, total daily users reached over the study period. It can be noted from Figure 7 above that the highest users engaged were on 31st May-2019, 25th March-2019 and, 10th Oct-2019 with 7982, 7709, 7448 users respectively while, the highest total daily reach was on 11th Oct-2019, 31st May-19 and, 25th March2019 with 70931, 60984, 56755 users, respectively. There is a direct relationship with the engaged users with the total reach; the more the engaged users, the more total users reached.

c) Daily Facebook Video Activity

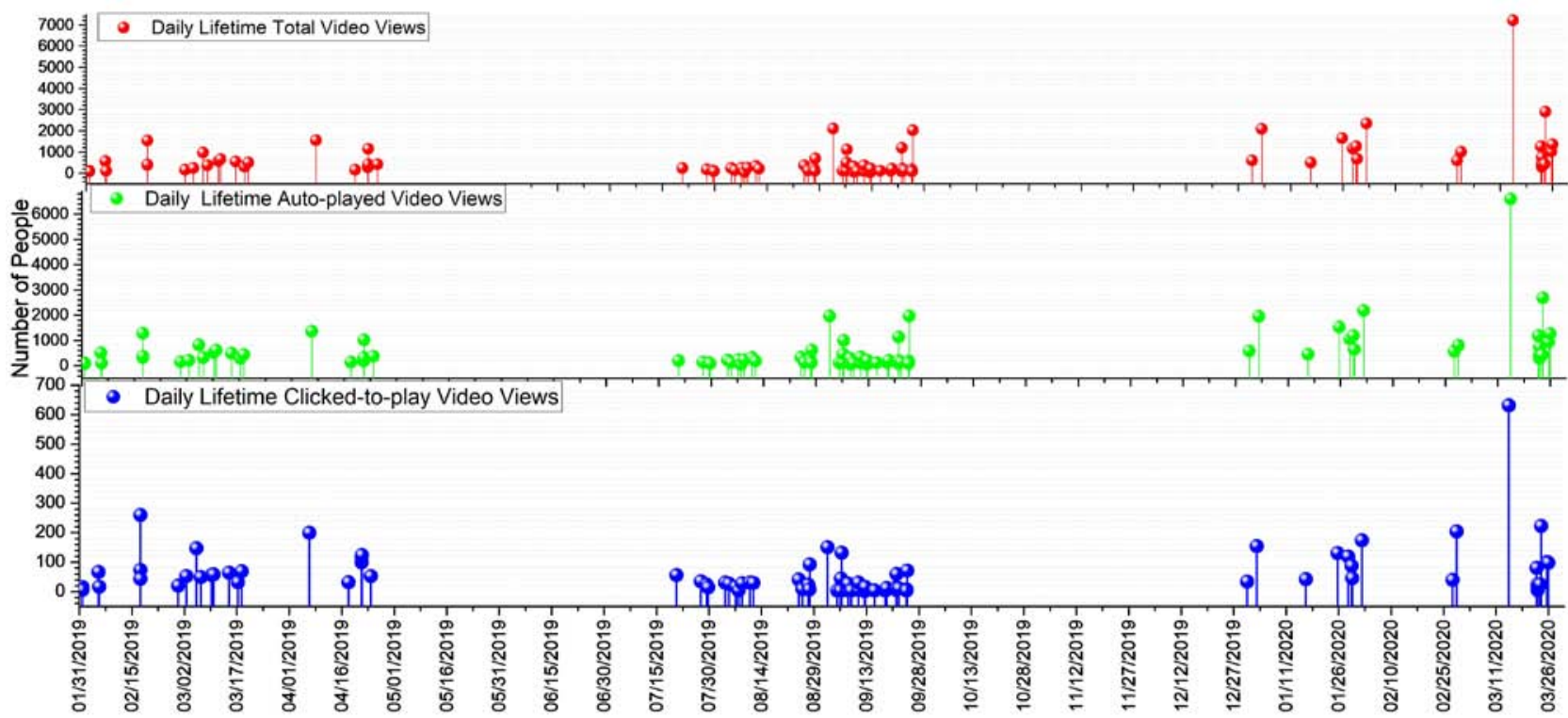

Figure 8: Daily count for KMD Facebook page Lifetime total video views, daily Auto-played video views and the daily Lifetime clicked-to-play video views reached

Figure 8 plots daily Lifetime total video views, daily Auto-played video views, and the daily Lifetime clicked-to-play video views reached. 53 weather and climate information videos were posted during the study period. The highest total video viewed was on 2nd Sep2019 at 9:12 am followed by 25th Sep-2019 at 5:36pm, and 7th April-2019 at 6:16 pm with 2109, 2028, 1562 total video views users, and 1959, 1957 and 1363 total 
Lifetime Auto-played Video Viewed respectively. Lastly, the highest total Lifetime Clicked-to-play Video Views was observed on 18th Feb-2019 at 0:09 am followed by 7th April-2019 at 6:16pm, and lastly on 2nd Sep-2019 at 9:12 pm with 260, 199, and 150 viewers respectively.

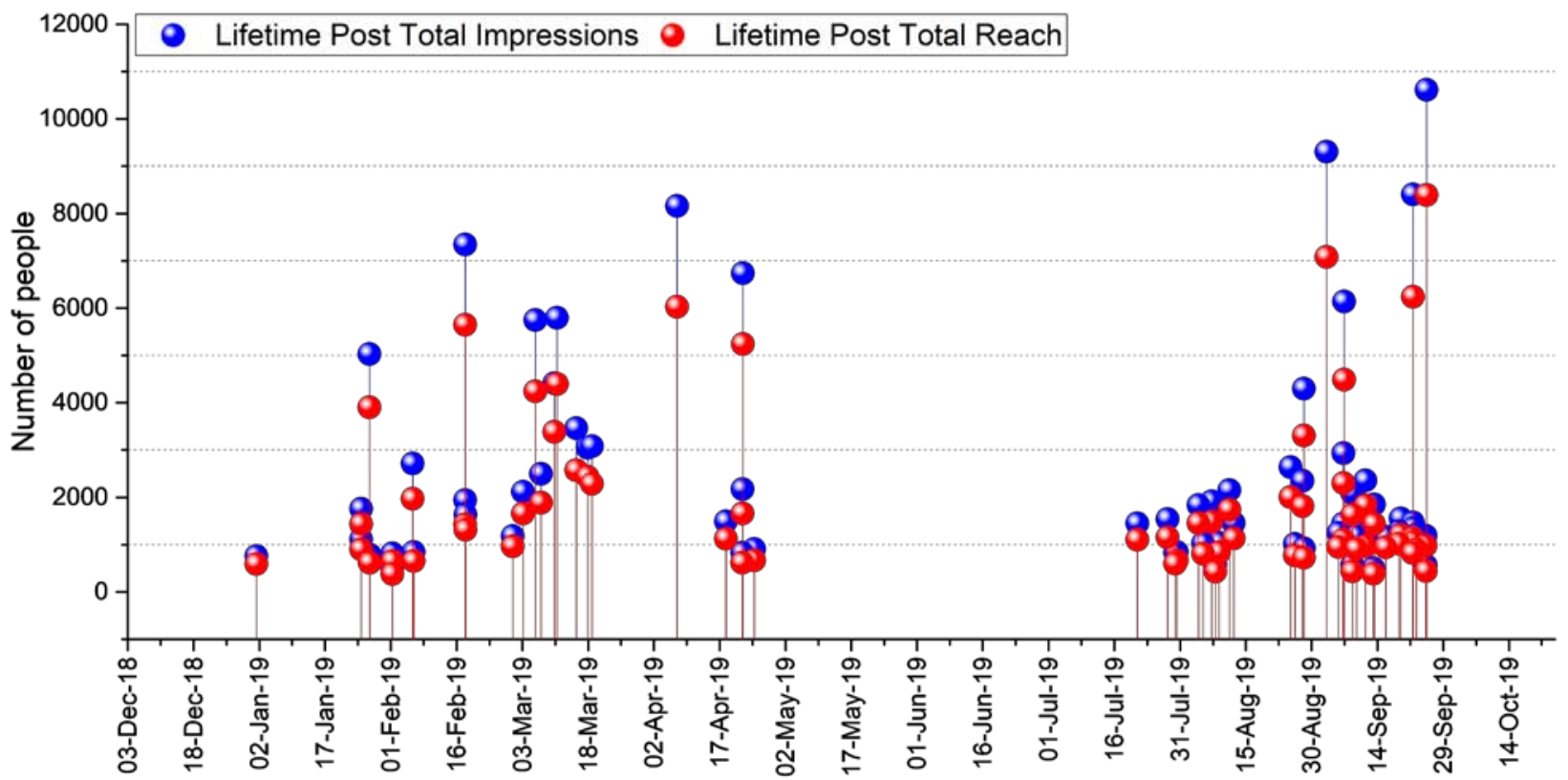

Figure 9: Number of post videos per day showing the daily video lifetime post total impressions and video lifetime post total reach

Figure 9 depicts the number of posts on a daily basis, stratified by posts by KMD. These weather and climate information video posts were infrequent throughout the study period, reaching a high of 10,617 users on 25th Sep-2019 at 5:36 pm for the lifetime post total impressions, followed by 9305 , and 8402 users on 2nd Sep-2019 at 9:12 pm, and 22nd Sep-2019 at 3:12 pm respectively. It was observed that the highest number of users for the daily video lifetime pot total reach was on 25th Sep-2019 at 5:36 pm with 8388 users followed by 708, and 6238 users on 2nd Sep-2019 at 9:12pm, and 22nd Sep-2019 at 3:12 pm respectively. Gender and Age
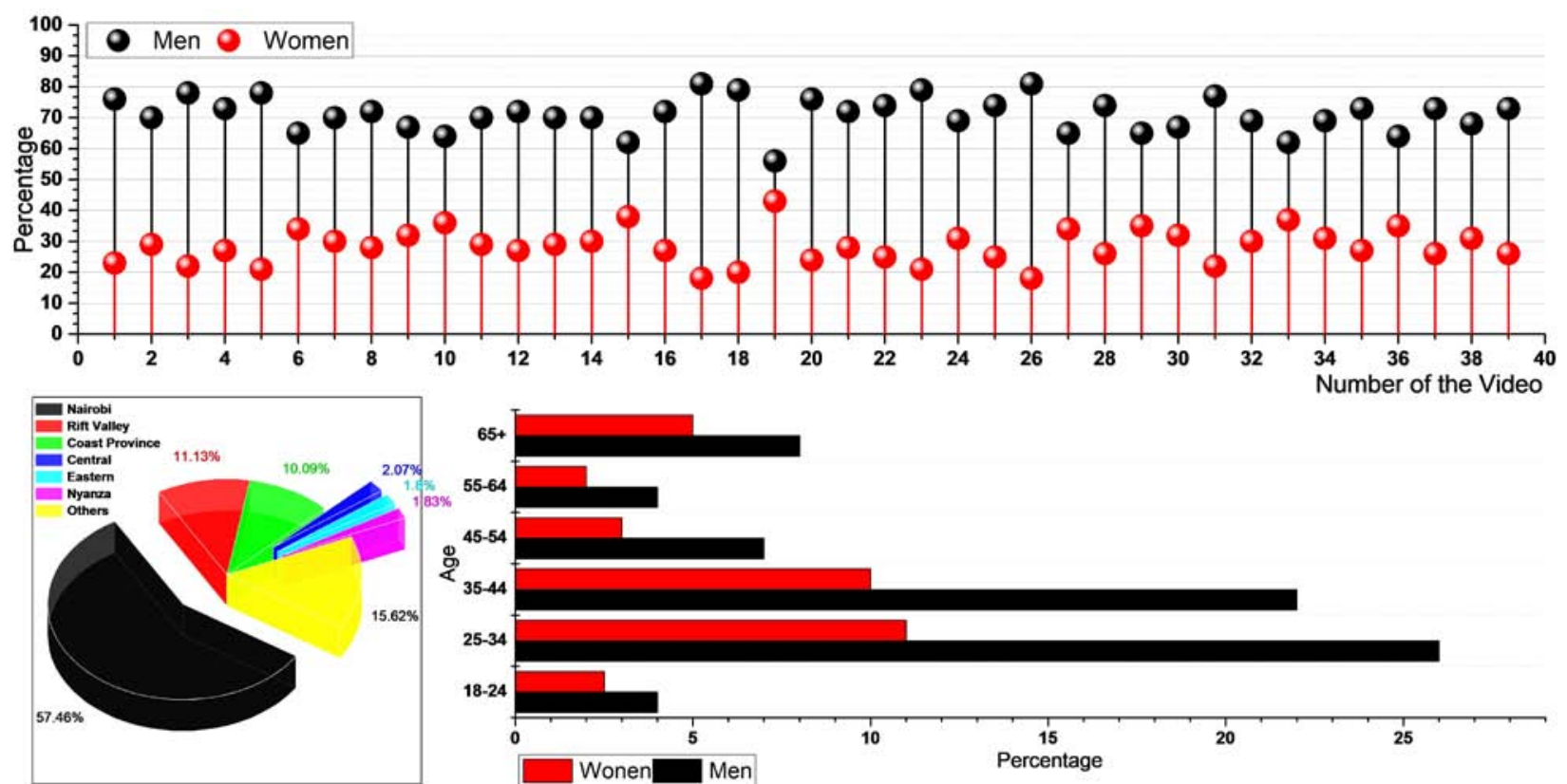

Figure 10: Socio-demographic characteristics of followers and their level of interaction on KMD social media accounts 
The socio-demographic characteristics of users are shown in Figure 10. It shows that $57.46 \%$ of users were from Nairobi, followed by $11.13 \%, 10.09 \%$, and $2.07 \%$ for Rift Valley, Coast, and Central Provinces respectively. While Eastern, and Nyanza Provinces accounted for $1.8 \%$ each. The remaining Provinces (Western, North Eastern, and Northwestern) accounted for $15.62 \%$. The majority of the users were in the age group of (25-34) years, an indication the majority of them were in active age. Also, $26 \%$ of the users were male, while $11 \%$ were female. Approximately $22.2 \%$ of male, and $10 \%$ female in the age group (35-44) years accounted for the second proportion of the users using social media, followed by $65+$ years, (45-54) years, (5564) years finally, the lowest percentage was from the age group (18-24) years. In general, it was observed that the total performance ratio $\sim 71 \%$ men: $\sim 29 \%$ of women were accessing weather and climate information through social media.

\section{Limitations and Future Work}

Weather and Climate Information are the most critical messages regarding the protection of life and property and should be prioritized in research like this. Facebook and Twitter have become a massive social network where many lifestyles interact on the same playing ground. This research aimed to identify Facebook and Twitter's place as a weather and climate information channel and continue a discussion about optimizing the use of these platforms; while it is not the top choice for weather information, it remains a choice for users.

While this study could stand to benefit from a larger user base, it was intentionally limited to only Facebook and Twitter users and followers. In this case, we aimed was to understand more about Facebook and Twitter as a weather and climate information channel. It is likely, though, that these two social media methods reached users less liable to rely on television, radio, newspapers, websites, and local/communities as an information channel. Thus, speculation about the preference for this other communication Media as a weather and climate information channel to the users may be reserved for another study with an alternate distribution method.

Earlier research recognized a necessity to understand weather communication on a variety of platforms (Rouge 2019). For example, scientists may examine when people prefer radio to a website, what type of weather information people prefer on Twitter versus Facebook, and how different segments of the users are using these channels. We also encourage similar studies on weather and climate information communication on Facebook, Twitter and other channels. So scholars should continue to work with practitioners to optimize communication on Facebook,
Twitter and all other social channels available to information clients (Resource 2009).

\section{Discussion And Conclusions}

The aim of this study was to demonstrate the impact of social media on the dissemination of weather and climate information by KMD. From the results, it is evident that social media was impactful as a means for communicating to weather and climate information. With its massive reach and ability to convey real-time information, social media could drive weather and climate information efforts. This study also clearly shows that the majority of the users $(\sim 71 \%)$ men access weather/climate information as compared to $\sim 29 \%$ of women. It is evident from the study that $(57.48 \%)$ of users were from Nairobi, which is the capital city of Kenya. A close observation also shows that $(11.13 \%$, and $10.09 \%$ ) of the users were from Nakuru and Mombasa which are also big towns in Kenya.

On Twitter, for example, messages occasionally go "viral"-they are transmitted and retransmitted (retweeted) many times in a short period. This happens for several reasons, most of which are related to the content of the message and the significance of the user who posted the original message within an expansive and active network of other users. The study findings also confirm the difference in access or the digital divide hypothesis. From the analysis its evident that higher percentages of young (25-34) years, male-26\%, and educated people are found to be more likely to receive more tweets and Facebook messages as compared to the other gender and age groups.

The study also found a bimodal relationship between the number of social media users and the age group with gender and percentage disparities. With increase in wellbeing due to employment opportunities, the users in social media initially increases, probably due to the increased access to the internet and mobile devices by age groups (25-34), and (35-44). After reaching a turning point of age group (45-64), the users; in social media decreases probably because of a lack of motivation among the wealthy class.

\section{Future Prospects}

The nature of the study is exploratory, in this paper, data was gathered only from Twitter and Facebook only. It may be possible that users from different other main stream media (TV, Radio, Newspapers, websites, mobile phones, etc.) have a different response. Future research should involve this media. Social media alone cannot be effective without enlarging it with other traditional media channels like radio, newspaper, or TV even though it is widely reported that the effectiveness of traditional media and their use is sharply falling. In general, it is worth having a 
social media strategy in place to manage the enormous challenges that social media brings.

This study offers interesting opportunities even though; it is not fully researched, it is however, worth replicating with Meteorological Agencies from the IGAD region to fully determine whether social media networks are effective as the finding of this study suggests.

\section{Vil. Recommendation}

Since this is a very vital and new phenomenon it is suggested that further research to study this phenomenon would be appropriate. From a meteorological agency standpoint, there is a huge potential on social media, and with the resources that KMD has got, they should consider expanding their social media strategies to include daily national TV and radio live streaming weather and climate information.

KMD should measure its social media metrics; for example, if they want to measure weather and climate awareness, they would need to monitor growth, likes, subscribers and product awareness. As for loyalty, the thing to look at would be engagement and influence. Engaging users online to implore recommendations would also give the KMD insight to co-innovate. KMD can also use the power of social media to implement other vertical services that could instantly bring value to the department in terms of its services.

Author Contributions: The research was conceptualized and written by MISIANI Zachary and LUN Yin The study design and data analyses were undertaken by MISIANI Zachary under the supervision of LUN Yin Additionally, Mwai, Lorez, Marta, Antonine, Xiaohan and Yanyan provided project oversight and supervision.

Funding: Sichuan Provincial Key Research Base of Philosophy and Social Sciences, Yi Cultural Research Center, "Research on the Legal Mechanism of the Religion and the Conservation of Biodiversity in the $\mathrm{Yi}$ Nationality Area" (YZWH1714); Project of Leshan Normal University, "Legislative Research on the Conservation of Biodiversity in Ethnic Areas" (WZD049) and "Comparative Research on the Law Norms of Biodiversity Conservation in Ethnic Areas" (XJR18010).

Acknowledgments: The authors would like to thank the Kenya Meteorological Department, Center for Ecological Civilization of Southwest Forestry University in China, IGAD Climate Prediction and Applications CentreICPAC for their support. We thank all the reviewers for their critical comments and suggestions, which have improved the quality of this manuscript significantly. The statements, findings, conclusions, and recommendations are those of the author(s) and do not necessarily reflect the views of KMD.

Conflict of interest: The authors have no conflict of interest to declare.
Notes: As at 31st March 2020, Kenya Meteorological Department (@MeteoKenya) had 22, 700 followers while KMD Facebook page (www.facebook.com/Kenya MeteorologicalDepartment/) has more than 26, 343 followers with 25, 597 total likes.

\section{References Références Referencias}

1. Ali, Zulqurnain, Muhammad Aqib Shabbir, Mashal Rauf, and Abid Hussain. 2016. "To Assess the Impact of Social Media Marketing on Consumer Perception Social Media Marketing Promotional Marketing Door to Door Marketing." 6(3): 69-77.

2. Babu, Aswathi Suresh, Dinesh Babu S, and D Harikrishnan. 2019. "Impact of Social Media in Dissemination of Information during a Disaster- a Case Study on Kerala Floods 2018." (7): 283-86.

3. Barnett, Julie, Ali Ziaee Bigdeli, and Steven Sams. 2016. "Social Media in Emergency Management: Twitter as a Tool for Communicating Risks to the Public." (July).

4. Cody, Emily $M$ et al. 2015. "Climate Change Sentiment on Twitter: An Unsolicited Public Opinion Poll.": 1-18.

5. Flesch, Benjamin, and Ravi Vatrapu. 2016. "Social Set Visualizer (SoSeVi) II: Interactive Computational Set Analysis of Big Social Data." (January 2018).

6. Huang, Lei. 2019. "The Communication Role of Social Media in Social Marketing: A Study of the The Communication Role of Social Media in Social Marketing: A Study of the Community Sustainability Knowledge Dissemination on Linkedln and Twitter." (May).

7. Joslyn, Susan, and Sonia Savelli. 2010. "Communicating Forecast Uncertainty: Public Perception of Weather Forecast Uncertainty." 195(April): 180-95.

8. Lu, Hao. "Applied Sciences Using Adverse Weather Data in Social Media to Assist with City-Level Traffic Situation Awareness and Alerting."

9. Macleod, David et al. 2020. "Are Kenya Meteorological Department Heavy Rainfall Advisories Useful for Forecast-Based Early Action and Early Preparedness ?" 72(April).

10. Management, Crisis, Crisis Management, and Crisis Management. 2014. "Social Media and Severe Weather: Do Tweets Provide a Valid Indicator of Public Attention to Severe Weather Risk Communication ?": 520-30.

11. Odhiambo, Christine Adhiambo. 2012. "SOCIAL MEDIA AS A TOOL OF MARKETING AND CREATING BRAND Barchelor of Business Administration."

12. Resource, National. 2009. "300 Billion Served." (December 2008). 
13. Rouge, Baton. 2019. "A Survey for Weather Communicators: Twitter and Information Channel Preferences": 595-607.

14. Severe, National. 2002. "Deaths in the 3 May 1999 Oklahoma City Tornado from a Historical Perspective." (May 1999): 354-61.

15. Slater, Morgan B, Emily Nicholas Angl, and Fok-han Leung. 2016. "Facebook as a Tool for Communication, Collaboration, and Informal Knowledge Exchange among Members of a Multisite Family Health Team": 29-34.

16. Thesis, A et al. 2015. "WEATHER WARNINGS ON SOCIAL MEDIA: USER PARTICIPATION AND RESPONSE." (May).

17. Xiao, Yu, Qunying Huang, and Kai Wu. 2015. "Understanding Social Media Data for Disaster Management." Natural Hazards (September).

https://sokodirectory.com/2020/05/164-dead-as-floodscontinue-to-sweep-across-29-counties/

https://www.nation.co.ke/news/Heavy-rains-kill-194Kenyans/1056-5544130-2bkd9fz/index.html 